\title{
Cuento
}

\section{Pequepandilla al rescate}

\section{Teresa Cenarro ${ }^{1}$, Esther Ruiz Chércoles 2, *}

1 Departamento de Pediatría, Radiología y Medicina Física, Área de pediatría, Facultad de Medicina, Universidad de Zaragoza

2 Pediatra, Centro de salud “María Jesús Hereza”, Leganés (Madrid); e-mail@e-mail.com; ORCID id

* Autor correspondencia: eruizc@salud.madrid.org; https://orcid.org/0000-0002-5174-5438

DOI: https://doi.org/10.37536/RIECS.2020.5.2.208

"Los niños y los pequepanda hemos salvado al mundo del malvado coronavirus". Así acaba la historia de esta pandilla de niños que se enfrentan con valentía e inteligencia a la epidemia del coronavirus. Un cuento para hablar con los niños de por qué hay que quedarse en casa y cómo cuidarse para defenderse de la infección.

Teresa Cenarro es pediatra y escribe; Esther Ruiz, también es pediatra, pero en este caso dibuja. Ambas construyen este precioso relato ilustrado para animar a todos los niños y ayudarles a entender lo que están viviendo en estos momentos.

Se trata de un cuento corto, promocionado por la AEPap (Asociación de Pediatría de Atención Primaria) que puede consultarse en el siguiente link https://www.familiaysalud.es/familias-queleen/te-regalo-un-cuento-0/pequepandilla-al-rescate.

(C) 2020 por los autores; Esta obra está sujeta a la licencia de Reconocimiento 4.0 Internacional de Creative Commons. Para ver una copia de esta licencia, visite http://creativecommons.org/licenses/by-nc-nd/4.0/. 